\title{
Public Transport Service Attributes: Travelers' Perception in Malaysia
}

\author{
Harifah Mohd Noor ${ }^{1}$, Abd Rahim Md Noor2, \\ $\mathrm{Na}^{\prime}$ asah Nasrudin ${ }^{3}$, Jurry Foo ${ }^{3}$ \\ ${ }^{1}$ Faculty of Humanities, Arts and Heritage, \\ Universiti Malaysia Sabah,88999, Kota Kinabalu, Sabah, Malaysia \\ 2 Faculty of Social Science and Humanities \\ Universiti Kebangsaan Malaysia 43600 Bangi, Selangor, Malaysia. \\ ${ }^{3}$ Faculty of Architecture Planning and Surveying, \\ Universiti Technology MARA,40450, Shah Alam, Selangor, Malaysia \\ harifah@ums.edu.my
}

\begin{abstract}
This paper identifies components of satisfaction of public bus service in Kota Kinabalu, Malaysia. Factor analysis is used to analyze 24 parameters satisfactions of public buses. This study succeeded in developing three dimensions of public bus service attributes, namely comfort, accessibility and safety and found that there is a slight difference in satisfaction between the minibus and bus transit, but users agreed that overcrowded and felt unsafe during the night were among the most significant attributes that affect their satisfaction. Transportation authorities can use these findings to enhance the quality of life of public transport users in the future.
\end{abstract}

Keywords: Public transportation, city bus, factor analysis, customer satisfaction

eISSN 2514-7528 @ 2018. The Authors. Published for AMER ABRA cE-Bs by e-International Publishing House, Ltd., UK. This is an open-access article under the CC BY-NC-ND license (http://creativecommons.org/licenses/bync-nd/4.0/). Peer-review under responsibility of AMER (Association of Malaysian Environment-Behaviour Researchers), ABRA (Association of Behavioural Researchers on Asians) and CE-Bs (Centre for EnvironmentBehaviour Studies), Faculty of Architecture, Planning \& Surveying, Universiti Teknologi MARA, Malaysia.

DOI: https://doi.org/10.21834/jabs.v3i10.311 


\subsection{Introduction}

The Quality of Life (QOL) has become a world concern. (Felce \& Perry, 1995) consider that $\mathrm{QOL}$ is a multi-dimensional sense of well being which can be categorised into five domains: physical, material, social, emotional, and developmental and activity. Transportation is thus an integral contributor to one's QOL as it is the bridge that enables an individual to visit and patronise local amenities. Steg \& Gifford (2005) have discovered the negative impact of increasing the number of cars on the road. (Bunting, 2004; Shuhana Shamsuddin et al, 2012) noted that if a society prioritises vehicle for personal use only, this will result in an increase in the demand, for cars. The resultant effect will be widespread traffic congestion, air and noise pollution, an unsociable society and exposing pedestrians and cyclists to danger (Na'asah et al 2013; Diyanah \& Hafazah 2012; Jalalkamali \& Ghraei, 2012)

Therefore, we need a public transport system that focuses on improving air quality and health. Even though Singapore, Tokyo and Hong Kong are known for their excellent public transport systems (Kenworthy,1995) they are not representative of the state of affairs worldwide as other countries are still facing challenges in attracting members of the public to use public transportation.

Somehow the biggest failure of public transport appears to be its inability to attract private car users. Public transport does not meet the current demand and thus forcing residents to opt to use private cars instead (Rakesh \& Shweta, 2010). Among the reasons commonly cited for the refusal to switch to public transportation are often late, unattractive stations, surly drivers and inadequate provision for people with disabilities (Bunting 2004).

Kota Kinabalu is the capital state of Sabah, located in the eastern part of Malaysia. The Kota Kinabalu Structure Plan indicates that one of the many objectives is to provide efficient and smooth running of public transport. However, previous studies have shown that public transport in the city of Kota Kinabalu is often associated with its ineffectiveness. The study of public transport in the city of Kota Kinabalu was initiated several years ago by the division of Traffic and Public Transport (2005), Kota Kinabalu Urban Transport Study (2007), and the Master Plan Study of Public Transport in Major Cities / Towns (2010). The reports found that the ineffectiveness can be categorised into five broad aspects, namely: (1) comfort, (2) reliability, (3) accessibility, (4) information and (5) safety.

According to the Sabah Development Corridor Blueprint, 2008-2025 (2007) the city of Kota Kinabalu needs public transport that is both efficient and effective. Therefore, the objective of the study is to determine the effectiveness of public transport from the customers' viewpoint. The research on public transport is limited to the use of the minibus and transit bus.

\subsection{Literature Review}

The quality of services provided can be evaluated by the perceptions of customers. (Hayes, 2008) determine customers' as 'soft index' which are subjective in nature that can be used as an indicator of the effectiveness which is focused on customers' perceptions because they are the direct users. In other words, it should be customer-oriented and meet the customers' 
needs and desires. Customers' perspective is measured using the Customer Satisfaction Survey (CSS), which will assist the authorities in improving the quality of services and increase the number of people using public transport. Through a questionnaire, the authorities will be able to identify all elements of public transport that should be addressed.

Several findings of the effectiveness of public transport have been identified through customers' perception surveys. Iseki et al (2007) revealed that accessibility and reliability are the top two key factors in evaluating the effectiveness of the services at the bus stop and bus terminal, and they are followed closely by the security factor. (Rasidah S. et al 2012) measured the customers' satisfaction perception in the context of bus services and found many factors that influence the effectiveness of public transport. The main factors are the physical condition, convenience, comfort and safety of the bus. On the other hand, Abd Rahim (2011) found that accessibility and reliability are key factors that contribute towards the ineffectiveness of public transport. In Malaysia, through the Government Transformation Programme, the Public Transport Roadmap has indicated that reliability and travel time, comfort and convenience, accessibility, interconnections, availability and capacity are the key indicators of an excellent public transport system

\subsection{Methodology}

Respondents were randomly chosen by giving them a form in selected vicinities of Kota Kinabalu City especially at bus stops, on buses, at shopping centres, as well as at government and private institutions. Data collection was conducted from Jun 15-20, 2013. The survey was targeted mostly at people who use public transport. The total sample size was 987 . The level of satisfaction with regard to public transport services was measured with a four-point Likert scale where 1 = strongly disagree, 2 = disagree; 3 = agree and 4 = strongly agree. Respondents were asked to rate the twenty-four items in terms of effectiveness on their experiences in having commuted on a minibus and transit bus. The twenty-four satisfaction items were gleaned from a literature review and also through a pilot study that reflected the respondents' experiences and problems faced when commuting via public transport. Descriptive statistics involving mean and standard deviation and factor analysis were used to analyse a total of 24 parameters that outlined the various statements against which the effectiveness of a public transport system can be graded

\subsection{Results and Discussions}

\subsection{Satisfaction Service Attribute Quality (Minibus and Transit Bus)}

Figure 1 depicts the mean value of user satisfaction of both the minibus and transit bus services. The mean score for 13 statements for the minibus service are slightly higher compared to those of the transit bus service. This means the level of satisfaction garnered or experienced while commuting on the minibus is best compared to that while taking the transit bus, despite the mean score of the transit bus service for seven statements being 
higher. Both the minibus and transit bus services share the same mean score for 4 statements: 'safe during the night', 'not crowded', 'easy access to bus stop' and 'cheap fare'. This shows that at least in these four aspects, users have the same experience for both the minibus and transit bus service.

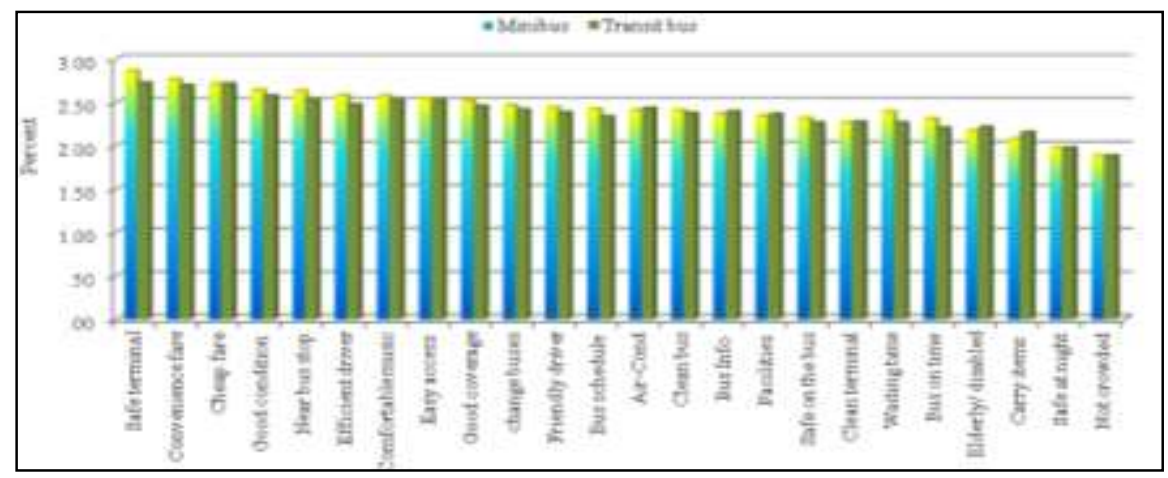

Fig. 1. Satisfaction service attribute quality for minibus and transit bus Analysis Factors Test For Effectiveness Of Public Transportation (Minibus And Transit Bus)

The factor analysis is performed using principal component analysis and varimax rotation with the objective to test the underlying factor structure of the data whereby items with a factor loading lesser than 0.50 were discarded and items that cross-loaded were also uninvolved. To determine the number of selected components only eigenvalues greater than 1.00 are considered. Within minibus users' perspective, as presented in table 1 , from 24 statements, 19 items were left to be used for further analysis where there was an item each from accessibility factor, i.e. 'bus on time' and safety factor, i.e. 'friendly driver' while two items from the comfort factor, i.e. 'bus schedule available', and 'not crowded in a bus' that were cross-loaded with the small coefficients of absolute value below 0.50 were deleted.

\subsubsection{Factor Analysis Test Towards Minibus Services}

Based on factor analysis results, minibus users' perspective, comfort is the most dominant factors that contributed 40.529 from 53.150 percent of the total variance with eigenvalues 9.727. This factor consists of eight items of effectiveness. The second factor is accessibility. Eigenvalues are 1.564 with a variance contribution is 6.516 percent. This factor contains nine items of effectiveness. The third factor is the safety with four items that contribute to the effectiveness of the total variance 6.102 percent with eigenvalue 1.465 . 
Table 1. Exploratory factor item loadings for minibus

\begin{tabular}{|c|c|c|c|}
\hline \multirow[t]{2}{*}{ Statements } & \multicolumn{3}{|l|}{ Factor } \\
\hline & 1 & 2 & 3 \\
\hline \multicolumn{4}{|l|}{ Comfort } \\
\hline Facilities in good condition & 0.817 & & \\
\hline Clean bus & 0.812 & & \\
\hline Air Condition & 0.719 & & \\
\hline Bus in good condition & 0.703 & & \\
\hline Easy to carry items & 0.632 & & \\
\hline Convenience for elderly, disabled & 0.620 & & \\
\hline Clean terminal & 0.619 & & \\
\hline Bus Info & 0.587 & & \\
\hline Bus on time & 0.512 & & \\
\hline \multicolumn{4}{|l|}{ Accessibility } \\
\hline Easy get bus & & 0.807 & \\
\hline Easy access to bus stop & & 0.733 & \\
\hline Cheap fare & & 0.720 & \\
\hline Convenient fare & & 0.638 & \\
\hline Good coverage & & 0.594 & \\
\hline Easy switch buses & & 0.582 & \\
\hline \multicolumn{4}{|l|}{ Safety } \\
\hline Safe on the bus & & & 0.742 \\
\hline Safe during night & & & 0.690 \\
\hline Safe terminal & & & 0.647 \\
\hline Efficient driver & & & 0.504 \\
\hline Cronbach's Alpha & 0.919 & 0.847 & 0.837 \\
\hline Total Variance Explained & 9.727 & 1.564 & 1.465 \\
\hline Percentage Variance Explained & 40.529 & 6.516 & 6.102 \\
\hline
\end{tabular}

Notes: Kaiser-Meyer-Olkin Measure of Sampling Adequacy $=0.938 ; \chi 2=12132.603$; Bartlett's Test of

Sphericity Significance $=0.000 ; \mathrm{df}=276$

Table 2. Exploratory factor item loadings for transit bus

\begin{tabular}{|c|c|c|c|}
\hline \multirow[t]{2}{*}{ Statements } & \multicolumn{3}{|c|}{ Factor } \\
\hline & 1 & 2 & 3 \\
\hline \multicolumn{4}{|l|}{ Comfort } \\
\hline Bus on time & 0.790 & & \\
\hline Bus info & 0.769 & & \\
\hline Short waiting & 0.731 & & \\
\hline Bus schedule & 0.730 & & \\
\hline Easy switch buses & 0.726 & & \\
\hline Good coverage & 0.722 & & \\
\hline Easy to get a bus & 0.698 & & \\
\hline Bus in good condition & 0.668 & & \\
\hline Clean bus & 0.638 & & \\
\hline Air Condition & 0.565 & & \\
\hline Convenience for elderly/disabled & 0.541 & & \\
\hline \multicolumn{4}{|l|}{ Accessibility } \\
\hline Convenient fare & & 0.703 & \\
\hline Cheap fare & & 0.680 & \\
\hline Easy access to bus stop & & 0.673 & \\
\hline Bus in good condition & & 0.653 & \\
\hline Music & & 0.637 & \\
\hline \multicolumn{4}{|l|}{ Safety } \\
\hline Safe during night & & & 0.672 \\
\hline Friendly driver & & & 0.669 \\
\hline Safe on the bus & & & 0.668 \\
\hline Efficient driver & & & 0.647 \\
\hline Cronbach's Alpha & 0.935 & 0.768 & 0.828 \\
\hline Total Variance Explained & 11.054 & 1.591 & 1.422 \\
\hline Percentage Variance Explained & 46.057 & 6.628 & 5.927 \\
\hline
\end{tabular}


Factor analysis loadings for minibus shows that all 19 items load heavily on their respective factors as the factor loadings of the items, as illustrated in table 1, were relatively large and positive, ranges from 0.504 to 0.817 . The first referred to item 'efficient driver' and the latter referred to item 'facilities in good condition' In terms of comfort factor, empirical results noted that statement 'facilities in good condition' had highest loading factor followed by 'clean bus', while statement 'easy to get a bus' fall under factor accessibility and statement 'feeling safe on a bus' for the safety factor, both lead the rest of the items to stand as having highest loading value. These are rated by respondents who used minibus as a mode of transportation as detailed in table 1.

\subsubsection{Factor Analysis Test Towards Transit Bus Services}

From table 2, transit bus users' perspective, comfort is the most dominant factors that contributed 46.057 from 58.611 percent of the total variance with eigenvalues 11.054 . This factor consists of 11 items of effectiveness. The second factor is comfort. Eigenvalues is 1.591 with a variance contribution is 6.628 percent. This factor contains nine items of effectiveness. The third factor is the safety with four items that contribute to the effectiveness of the total variance 5.927 percent with eigenvalue 1.422. Further investigation of the study in Table 2 revealed that within an accessibility factor, a statement 'convenient fare' had uppermost loading value among five factorised items. Respondents who used transit bus to also do concern on safety factor where statements such 'safe at night' (loading $=0.672$ ), 'friendly driver' (loading $=0.669$ ), and 'feel safe on a bus' (loading $=0.668$ ) are rated high within four-point Likert scale.

\subsection{Perceptions Towards City Bus Services}

\subsubsection{Factor 1 : Comfort}

This factor is the main contributor in affecting people's perceptions of the effectiveness of both minibus and bus transit service, and it includes the physical condition, the convenience and comfort that experiences while being on the bus or at the terminal. The figure 1 used earlier reveal that the respondents are satisfied with a safety at the bus terminal, but do not appreciate the congestion or overloaded buses and lack of facilities for the elderly and disabled, carry items and clean terminal. Soltani et al. (2012) in their research in Kuala Lumpur about accessibility for the disabled in public transport terminal, found out that there are a lot of improvements needs to be done, and the feeling of unsafe among women travelers is still very high when they are using a public transport (Rohana et al. 2012). The current system that allows permits to be given out to individual bus operators has resulted in too many permits being issued and has led to bus operators competing with each other. To get more profits, buses that are managed by bus entrepreneurs with more than 10 years are taking more passengers than they should. Travel will only take place when the bus is overloaded, and they will also choose a route that will give more profits. 


\subsubsection{Factor 2: Accessibility}

The minibus is better in accessibility aspect as according to the respondents such as waiting time, good coverage and bus on time (see figure 1). Its small size enables it to pick up and set down passengers relatively easily. According to Abd Rahim (2004), the advantage of using minibus against the larger bus in its ability to manoeuvre easily reasonable speed due to its size and organisational form. Even though the transit bus has the capacity to accommodate more passengers as compared to the minibus, but the latter that cannot provide optimum frequencies. The average shows that an inaccurate itinerary and waiting time are the main problem. As the Final Report, Public Transport Fares In Peninsular Malaysia, the Ministry of Entrepreneur and Cooperative Development (MECD, 2008), stated that the main problem of the transit bus is the failure to ensure the accuracy of the time while taking passengers, too much unhealthy competition, overlapping routes, and higher operating costs.

\subsubsection{Factor 3: Safety}

It shows that feeling safe while inside the bus and feeling safe at night are the major problems for both bus modes (minibus and transit bus). However, respondents are satisfied with the level of security during the day. This suggests that the efficiency and discipline of the driver is not the main cause of the lack of safety on public transportation services, but rather the problem arises due to the lack of lighting infrastructure and congestion when boarding the bus.

\subsection{Conclusion}

Although some research has been done regarding the effectiveness of public transportation, there are few studies regarding the dispute between the effectiveness of the use of a minibus versus that of a transit bus. The contribution of this study is to identify the primary components of satisfaction among the users of both a minibus and a transit bus. This study showed that a minibus service is noteworthy in terms of the level of comfort and convenience that it affords its users. Although there is no problem about the frequency of access, the horrendous state of the bus is causing discomfort to users. Bus size and bus design are integral in influencing consumer's convenience and comfort. For the transit bus, accessibility and reliability are key problems that need to be addressed. Some improvements, especially in the operating system should be reviewed for short term and establishing viable public transport modes or alternatives, e.g. trams, light rail transit (LRT) and integrated bus and rail line for the long term planning. This feedback can be utilized as a useful tool for authorities and other agencies involved in helping them plan public transport in the future.

\section{Acknowledgement}

The authors would like to express our gratitude to Universiti Malaysia Sabah (UMS and Universiti Kebangsaan Malaysia (UKM) for their generous contribution towards this research. 


\section{References}

Abd Rahim, et al. (2011). Assessing public transport service attributes using factor analysis. Applied Sciences Journal $13,07-12$.

Bunting, Mark. (2004). Making public transport work. Canada: McGill-Queen's University Press.

Diyanah et al. (2012). Implications of walkability towards promoting sustainable urban neighbourhood. ProcediaSocial and Behavioral Sciences, 50, 204-213.

Felce, David, \& Perry, Jonathan. (1995). Quality of life: Its definition and measurement. Research in developmental disabilities, 16(1), 51-74.

Hayes, Bob E. (1998). Measuring customer satisfaction: survey design, use, and statistical analysis methods: ASQ Quality Press.

Jalalkamali, N. et al. (2012). The Cycling Potentials of Malaysian Students in UiTM Campus. Procedia-Social and Behavioral Sciences, 50, 941-949.

Kenworthy, Jeff. (1995). Automobile dependence in Bangkok: An international comparison with implications for planning policies. World Transport Policy and Practice, 1(3), 31-41.

Malaysia. (2007). Kota Kinabalu Urban Transport Study Kota Kinabalu: Ministry of Works Malaysia.

Na'asah, N et al. (2013). Urban Residents' Awareness and Readiness for Sustainable Transportation Case Study: Shah Alam, Malaysia. Procedia-Social and Behavioral Sciences, 105, 632-643

Noriza, R. et al. (2013). Perceptions of the Urban Walking Environments. Procedia-Social and Behavioral Sciences, 105, 589-597.

Rasidah, S et al (2012). The Relationship between Crime Prevention through Environmental Design and Fear of Crime. Procedia-Social and Behavioral Sciences, 68, 628-636.

Rohana Sham et al. (2012). Travel safety fear factor among vulnerable group of travelers: the urban scenario. Procedia - Social and Behavioral Sciences, 50(0), 1033-1042. doi: ttp://dx.doi.org/10.1016/j.sbspro.2012.08.103

Sabah. (1999). Public transport masterplan study for Kota Kinabalu, Sandakan and Tawau Final Report Summary. Sabah: Department of State Development.

Soltani, et al. (2012). Accessibility for disabled in public transportation terminal. Procedia - Social and Behavioral Sciences, 35(0), 89-96. doi: http://dx.doi.org/10.1016/j.sbspro.2012.02.066

Shuhana Shamsuddin, et al. (2012). Walkable environment in increasing the liveability of a city. Procedia - Social and Behavioral Sciences, 50(0), 167-178. doi: http://dx.doi.org/10.1016/j.sbspro.2012.08.025

Steg, Linda, \& Gifford, Robert. (2005). Sustainable transportation and quality of life. Journal of transport geography, 13(1), 59-69. 